\title{
Snakebites Reported to the Kentucky Regional Poison Control Centers for the Years 2012-2016
}

\author{
James Buchanan, MD; Jeffrey Thurman, MD; Charles Hargis, MD; Lauren Kirkpatrick, PharmD; \\ Martin Huecker, MD
}

University of Louisville, West Lafayette, Indiana

\begin{abstract}
Introduction-Snake envenomations cause significant morbidity and mortality. The goals of this study were to assess the epidemiology of snakebites in Kentucky and treatment strategies used by physicians reporting to the Kentucky Regional Poison Control Centers.

Methods-This was a descriptive epidemiologic study compiling clinical data on snakebites reported to the Kentucky Regional Poison Control Centers from 2012 to 2016. We built a database of the patient demographics, treatment, and clinical course of each snakebite reported in the study period. Attention was paid to all antivenom interventions and use of contraindicated therapies.

Results-We compiled 674 total records. Patient age was $34 \pm 18$ y (mean \pm SD), with males $(71 \%)$ predominating. Most (97\%) bites were to a distal upper or lower extremity. The majority (78\%) occurred at a private residence. Most reports came between May and September (88\%). Of the 674 patients, $24 \%$ $(n=159)$ were classified as moderate or severe. Two hundred thirty $(34 \%)$ patients were admitted to the hospital. Forty-six patients $(7 \%)$ received surgical consultation, and $12(2 \%)$ underwent surgical intervention. One hundred fifty-three patients received antivenom, with $6 \pm 3$ vials used per patient. Length of stay was $3 \pm 2 \mathrm{~d}$ when antivenom was administered and $2 \pm 2 \mathrm{~d}$ when not administered. Six cases of coagulopathy were noted. Multiple contraindicated therapies were noted.

Conclusions-Snake envenomations are a prevalent public health concern for residents of Kentucky, chiefly during summer months. Significant medical intervention is being performed for many patients, with a high prevalence of contraindicated therapies. More data are needed to fully characterize the epidemiologic impact and appropriateness of the interventions being applied.
\end{abstract}

Keywords: envenomation, antivenom, copperhead, pit viper, debridement, rattlesnake

\section{Introduction}

The Centers for Disease Control and Prevention estimates that $>7000$ people per year sustain a snakebite, although studies have shown a range between 5000 and $9000{ }^{1,2}$ When these bites are the result of a venomous snake, they represent an uncommon but important illness owing to the potential for prolonged morbidity and, rarely, mortality. ${ }^{1,3}$ Although death is a rare sequela of snakebites, with 0 to 4 reported per year, the number would likely be higher without proper medical care. ${ }^{4,5}$

Corresponding author: Charles Hargis, MD, University of Louisville, 2704 N 745 W., West Lafayette, IN 47906; e-mail: cwhargis@gmail.com. Submitted for publication March 2020.

Accepted for publication January 2021.
Victims are most often bitten on their distal extremities, lower more than upper, and are more likely to be Caucasian and male. ${ }^{1,4}$ The most common age range of a snakebite patient is 20 to $30 \mathrm{y}$, although there is a small peak in children below the age of $12 \mathrm{y} \cdot{ }^{1,4,6,7}$ Bites typically occur at dawn and dusk, during the snake's natural predatory activities, and in the warmer months of May through October. ${ }^{7}$ There are multiple species of venomous snakes in the United States, including rattlesnakes, copperheads, cottonmouths/water moccasins, and coral snakes. The state of Kentucky itself is home to 4 types of venomous snakes, all in the Crotalinae subfamily of Viperidae, commonly referred to as "pit vipers": copperheads (Agkistrodon contortrix), cottonmouths (Agkistrodon piscivorus leucostoma), timber rattlesnakes (Crotalus horridus), and the western pygmy rattlesnake (Sistrurus miliarius streckeri). ${ }^{8}$ Copperheads and timber 
rattlesnakes are widely distributed throughout the state, but both the western cottonmouth and western pigmy rattlesnake are generally located only in the most western parts of the state. ${ }^{8}$

Snake venom is a complex mixture of biologically active compounds that vary by region, species, diet, and genetics. ${ }^{7}$ Crotalinae venom in particular typically contains a variety of compounds that have cytotoxic, myotoxic, and hemotoxic compounds that can result in both local tissue damage and systemic effects such as hemolysis and coagulopathies. ${ }^{9,10}$ Although less common, crotaline venom may also contain neurotoxic compounds that can result in weakness, cranial nerve palsies, and potentially respiratory failure. ${ }^{5,7}$ Timber rattlesnakes are an example of one such snake that commonly possesses a neurotoxin. ${ }^{7}$ Typical local symptoms include pain, erythema, and edema that can potentially encompass an entire limb. ${ }^{4,11-13}$ These localized symptoms may worsen in the first few days after envenomation and persist for 14 to $21 \mathrm{~d}$, and occasionally longer. ${ }^{4}$

Envenomations are classified into 4 broad categories: dry bite, mild envenomation, moderate envenomation, and severe envenomation. ${ }^{7,14}$ Dry bites result in no localized or systemic symptoms and no coagulopathy on serial measures. Mild to severe envenomations are a spectrum of progressive localized and systemic symptoms, with moderate and severe envenomations potentially having signs of coagulopathy. Severe envenomations can result in severe localized edema and pain, gross coagulopathies on laboratory assessment, clinically significant bleeding, hypotension, angioedema, or anaphylaxis.

Crotaline antivenom is given as an initial starting dose of 4 to 6 vials with repeat dosing until initial control is obtained. Once initial control is obtained, maintenance dosing of 2 vials at 6,12 , and $18 \mathrm{~h}$ is recommended. ${ }^{11,15}$ Expert consultation with a local poison control center is available to aid in the management of patients to help guide providers on antivenom administration and avoidance of contraindicated therapies.

Several therapies are not recommended because they do not improve outcomes over antivenom and can potentially result in more harm to patients. The use of ice, local incision, suction at the bite site, tourniquets, compression bandages/pressure immobilization, and prophylactic fasciotomies can result in more tissue damage without any benefits. ${ }^{16}$ Use of nonsteroidal antiinflammatory drugs should be avoided for pain control in favor of opiates because they may potentiate venom's effects on platelet aggregation and coagulation. Antibiotics should also be avoided because secondary infections of snakebites are rare and antibiotics have not shown any benefit in outcomes. ${ }^{17}$ Despite these recommendations, individual practice still varies. ${ }^{7,14}$
The purpose of this study was to identify the demographics of snakebite incidents, snakebite victims, and outcomes in the state of Kentucky. We also made note of the use of antivenom, the specific doses of antivenom given, and any documented use of a contraindicated therapy.

\section{Methods}

This study was reviewed by the University of Louisville institutional review board and was determined to be exempt according to 45 CFR 46.101(b). We accessed records from the Kentucky Regional Poison Control Center (KRPCC) with a diagnosis of snakebite between the years of 2012 and 2016, which provided 674 unique records. From these records, multiple data points were extracted and entered manually into a database by the authors. Patient characteristics including age, sex, and potential intoxication were recorded. Envenomation information including location on body; time, date, and geographic location of the bite; and type of snake reported was also recorded. Location on body was grouped into the following categories: head and neck; torso, including chest, abdomen, and back; proximal upper extremity, defined as proximal to and including the elbow; distal upper extremity, defined as distal to the elbow; proximal lower extremity, defined as proximal to and including the knee; and distal lower extremity, defined as distal to the knee. Location where the bite occurred was grouped into the following categories: private residence, public area or park, zoo, or other. Type of snake reported was broken down into the following categories: copperhead, cottonmouth, rattlesnake, unknown, and other. Signs and symptoms of the bite were also obtained from the description provide, $d$ including pain, swelling, ecchymosis, blister or bullae, nausea and/ or vomiting, paresthesia, fasciculations, and necrosis. Severity of bite was defined as dry if there was no pain or swelling, mild if localized pain/swelling did not cross a joint, moderate if pain or swelling crossed $>1$ joint but $\leq 2$ joints, and severe if the swelling affected $>2$ joints, a coagulopathy was detected, or hypotension occurred. Coagulopathy was defined as an international normalized ratio greater than 2.0, prothrombin time greater than 20 , platelet count less than 50,000, or fibrinogen less than 50 .

To help ensure inter-rater reliability, the first 25 cases were reviewed by the 4 reviewers as a group to ensure each rater was familiar with the format of KRPCC records and the aforementioned bite severity definitions. In the event that KRPCC records presented a questionable case, group consensus of the 4 reviewers was obtained. Data are presented as mean $\pm \mathrm{SD}$ or percentage, as appropriate. 
Table 1. Victim age distribution of snakebite reported for the years 2012 to 2016

\begin{tabular}{lcc}
\hline Victim age $(y)$ & Number & Percentage \\
\hline$<18$ & 137 & 20 \\
$18-35$ & 220 & 33 \\
$36-55$ & 199 & 29 \\
$>55$ & 94 & 14 \\
Unknown age & 24 & 4 \\
\hline
\end{tabular}

\section{Results}

\section{DEMOGRAPHICS}

Males comprised $71 \%$ of snakebite victims reported to the KRPCC (Table 1). Age was $34 \pm 18$ y for males and $34 \pm 20 y$ for females. Ninety-seven percent of bites were to a distal upper or lower extremity (48\% each). Males were more often bitten on the upper extremities $(61 \%)$, and females were more often bitten on the lower extremities (75\%). Seventy-eight percent of bites occurred at a private residence. Seventeen people were reportedly intoxicated at the time the snakebite occurred. Eighty-eight percent of snakebites reported occurred in the months of May through September (Figure 1). July had the most snakebites for each year examined. The time of day for calls to the KRPCC was approximately $5 \pm 6$ hours after noon.

Copperheads made up 53\% $(n=358)$ of reported snakebites in which the snake could be identified. Rattlesnakes made up 3\% $(\mathrm{n}=20)$. Thirty-seven percent $(n=46)$ of snakebites reported were from an unknown type of snake. The remainder was grouped into an "other" category that included nonvenomous snakes only.

\section{CLINICAL COURSE}

One hundred fifty-nine (24\%) snakebites reported were classified as moderate or severe based on the symptoms reported to the KRPCC (Table 2). Symptomatically, $88 \%$ of

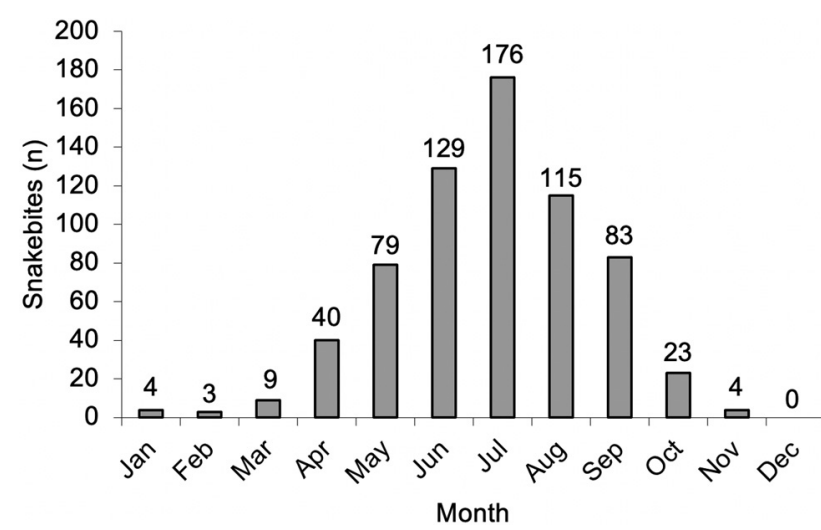

Figure 1. Distribution of snakebites reported by month. patients reported pain, with 71 and $28 \%$ of patients reporting swelling and ecchymosis, respectively. Nausea and vomiting were the most common systemic symptoms at $9 \%$. Six cases of coagulopathies were noted; 5 of these were from rattlesnake bites, and 1 was from an unknown type of snake.

Thirty-four percent, or 230 patients, were admitted to the hospital; $69(10 \%)$ of those were admitted to the intensive care unit. Fifty-one percent of patients who presented to the emergency department were discharged home, with another $4 \%$ signing out against medical advice. Twenty patients returned to the emergency department within $24 \mathrm{~h}$ (6\% of those discharged from the emergency department). Forty-six patients received surgical consultation, and 12 underwent surgical intervention. Seven patients underwent fasciotomies, and 1 patient received a partial digit amputation. Of the patients who received fasciotomies, 5 bites were from copperheads and 2 were from an unknown type of snake. The amputation resulted from a bite from an unknown type of snake. Five patients received debridement. Debridement was performed on 2 copperhead envenomations, 1 rattlesnake envenomation, and bites from 2 unknown snakes. Fifty percent of patients who received surgical intervention did not receive antivenom. One death was reported in a person who was bitten on a distal extremity by a rattlesnake.

Forty-one percent of envenomations received antivenom in this cohort. One hundred fifty-three patients received antivenom, with an initial and total dose of $4 \pm 1$ and $6 \pm 3$ vials, respectively. The maximum number of vials given was 21 . Of bites described as moderate or severe, 55 and $79 \%$ received antivenom, respectively. Length of stay was $2 \pm 2 \mathrm{~d}$, with lengths of stay of $3 \pm 2 \mathrm{~d}$ and $2 \pm 2 \mathrm{~d}$ if antivenom was administered and not administered, respectively. Contraindicated therapies including initial antibiotic administration, application of ice, nonsteroidal anti-inflammatory drug or aspirin administration, tourniquet application, steroids, and incision can be seen in Table 3. Antibiotics were the most commonly used contraindicated therapy.

Two hundred thirty (34\%) patients were admitted to the hospital. Length of stay in the hospital was $3 \pm 2$ and $2 \pm 2$ $\mathrm{d}$ with and without antivenom, respectively. Sixty-four percent of those who were admitted and received antivenom had moderate or severe snakebites, compared to $38 \%$ of those who were admitted without receiving antivenom.

\section{Discussion}

\section{DEMOGRAPHICS AND LOCATION WITHIN KENTUCKY}

The male sex of victims and distal extremity predominance of envenomations is consistent with prior studies in the United States. ${ }^{18-20}$ A concentration of envenomations 
Table 2. Classification of snakebite severity for the years 2012 to 2016

\begin{tabular}{llrr}
\hline Type of bite & Definition & Incidence & Percentage of total bites \\
\hline Dry & No pain or swelling & 239 & 36 \\
Mild & Local pain/swelling crossing $\leq 1$ joint & 273 & 40 \\
Moderate & Pain/Swelling crossing 2 joints & 141 & 21 \\
Severe & Pain/Swelling crossing $>2$ joints, coagulopathy, hypotension & 19 & 3 \\
Unable to determine & & 2 & 0 \\
\hline
\end{tabular}

in the summer months is also consistent with prior studies. ${ }^{19,20}$ The proclivity of males to be bitten on an upper extremity and females to be bitten on a lower extremity was consistent with data from the North American Snakebite Registry. ${ }^{20}$ Hospital admission rates were similar to the nationwide figure of $29 \%$. $^{21}$

The concentration of snakebites reported to the KRPCC around the state of Kentucky is heat mapped in Figure 2. Metropolitan areas demonstrated a higher concentration of snakebites reported. This is possibly secondary to their higher populations. The mountainous areas of southeastern Kentucky also demonstrated higher relative concentrations of snakebites compared with the rest of the state, despite not containing populous areas. The cause of this concentration is unclear. One possibility is the practice of snake handling in certain religious practices that are common in Appalachia.

\section{ANTIVENOM ADMINISTRATION}

Previous studies have shown that $72 \%$ of copperhead bites and $84 \%$ of all pit viper bites received antivenom. ${ }^{19}$ This was significantly higher antivenom administration than in this cohort. Bite severity between these groups is difficult to compare given the available data. Increased bite severity correlated highly with antivenom administration, with $79 \%$ of severe bites receiving antivenom and less than $1 \%$ of dry bites receiving antivenom. Extremes of age did not seem to be a factor: The distribution of antivenom administration to patients aged $<18$ and $>65 \mathrm{y}$ was similar to the distribution of those ages in the cohort. The often-recommended initial dose of 4 to 6 vials $^{2}$ is consistent with the KRPCC recommendation and is consistent with what was administered in this cohort.

\section{CONTRAINDICATED THERAPIES}

Several therapies were reported frequently in our study despite typically being considered contraindicated therapies that show no benefits and occasionally cause harm ${ }^{7,14}$ (Table 3). Antibiotics were the most commonly used contraindicated therapy at $21 \%$ of snakebites reported. Several contraindicated therapies were administered by emergency medical service personnel, including incision, suction, tourniquets, and application of ice. Incision and suction in particular have been associated with local tissue injury and should be avoided when treating snakebites. ${ }^{14,22,23}$ Nonsteroidal anti-inflammatory drugs, although contraindicated owing to concern about platelet dysfunction, have little evidence to suggest they should be avoided in copperhead bites, the main source of venomous snakebites in Kentucky. ${ }^{14,24}$ Tourniquets, although generally not recommended, have mixed data. ${ }^{14,22}$

Antibiotics are relatively contraindicated because crotaline envenomations are considered as at low risk for secondary infection, but antibiotic administration is associated with side effects and potential harm. ${ }^{17}$ The appropriateness of antibiotic use in this cohort is difficult to determine given the limited clinical information obtained through KRPCC records. Inflammation versus infection can be challenging to assess when determining whether to administer or prescribe antibiotics. The timing of the presentation in relation to the bite and expert consultation are important factors in determining whether antibiotics are indicated. ${ }^{14}$ Previous studies have shown a much lower rate of antibiotic use (8 vs $22 \%$ ) than what was administered per the KRPCC records. ${ }^{20}$

\section{LIMITATIONS}

KRPCC's records are not standardized; therefore, much of this data was collected from free text fields in KRPCC's database. These data represent an incomplete medical record and do not provide a complete clinical picture of each snakebite. Data were also heterogenous to

Table 3. Contraindicated therapies reported for the years 2012 through 2016

\begin{tabular}{lcc}
\hline Therapy & Incidence Percentage \\
\hline Ice & 28 & 4 \\
Incision & 5 & 1 \\
Suction & 7 & 1 \\
Tourniquet & 19 & 2 \\
Steroids & 16 & 2 \\
Aspirin/Nonsteroidal anti- & 20 & 3 \\
$\quad$ inflammatories (ASA/NSAIDS) & & \\
Antibiotics & 146 & 22 \\
\hline
\end{tabular}




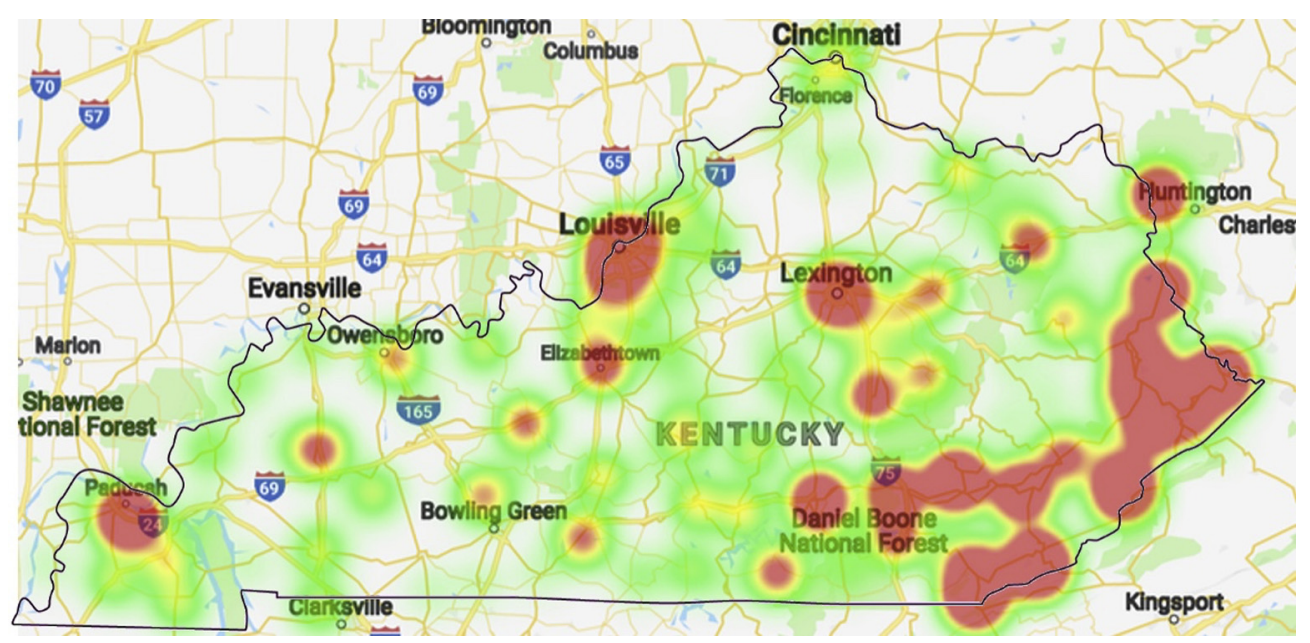

Figure 2. Heat map representing the concentrations of snakebites reported to the Kentucky Regional Poison Control Centers mapped by the zip code of the caller. Map generated from Google Maps and reproduced in accordance with their permissions guidelines.

a large extent given the free text nature of the records and the difficulty of obtaining follow-up information from busy hospital staff. Although efforts were made to increase interrater reliability, there was some potential for heterogeneity in snakebite severity assigned across raters.

Snakebite figures are likely underreported to KRPCC. A comparison of snakebite-related Missouri poison control center calls and emergency department visit data revealed that only $18 \%$ of snakebite-related emergency department visits had a corresponding call to the state poison control center. ${ }^{25}$ Snake species were often selfreported, and the reliability of a person's ability to properly identify snake species was not determined in this study. A previous study determined laypersons could distinguish between a venomous and nonvenomous snake $81 \%$ of the time. ${ }^{26}$ The 5 -y time period for which data was collected may be insufficient to properly encompass trends in snakebites in Kentucky.

Reporting bias may affect the distribution and number of snakebites reported to KRPCC. Hospitals in certain areas may call the KRPCC to report bites more frequently than other hospitals. Individual providers who work in certain areas may also be more inclined to report snakebites to the KRPCC than others. Local resident knowledge of KRPCC's availability to assist with snakebites may also affect reporting to KRPCC.

\section{Conclusions}

This study demonstrated that crotaline envenomations continue to be a public health issue for residents of Kentucky during the summer months. Significant medical intervention is being performed for many of these Kentucky residents. Our data are in line with previous studies in regard to the demographics of crotaline envenomation victims. Despite numerous guidelines recommending against some therapies, they continue to be used in the state of Kentucky, particularly antibiotics. Emergency medical service personnel likely need additional training given the contraindicated therapies they are performing. More data are needed to fully characterize the full epidemiological impact and appropriateness of interventions being applied.

Author Contributions: Study concept and design (JB, JT, MH); acquisition of the data (JB, JT, $\mathrm{CH}, \mathrm{LK})$; analysis of the data (JB, JT, $\mathrm{CH}, \mathrm{MH}$ ); drafting of the manuscript (JB, JT, $\mathrm{CH}, \mathrm{MH}$ ); critical revision of the manuscript (JB, JT, CH, MH); approval of final manuscript (All). Financial/Material Support: None.

Disclosures: None.

\section{References}

1. Seifert SA, Boyer LV, Benson BE, Rogers JJ. AAPCC database characterization of native US venomous snake exposures, 2001-2005. Clin Toxicol (Phila). 2009;47(4):327-35.

2. Lavonas EJ, Khatri V, Daugherty C, Bucher-Bartelson B, King T, Dart RC. Medically significant late bleeding after treated crotaline envenomation: a systematic review. Ann Emerg Med. 2014;63(1):71-8.

3. Spiller HA, Bosse GM. Prospective study of morbidity associated with snakebite envenomation. J Toxicol Clin Toxicol. 2003;41(2):125-30.

4. Walter FG, Stolz U, Shirazi F, McNally J. Epidemiology of severe and fatal rattlesnake bites published in the American Association of Poison Control Centers' Annual Reports. Clin Toxicol (Phila). 2009;47(7):663-9.

5. Gerardo CJ, Vissoci JRN, Evans CS, Simel DL, Lavonas EJ. Does this patient have a severe snake envenomation?: the rational clinical examination systemic review. JAMA Surg. 2019;154(4):346-54. 
6. O’Neil ME, Mack KA, Gilchrist J, Wozniak EJ. Snakebite injuries treated in United States emergency departments, 2001-2004. Wilderness Environ Med. 2007;18(4):281-7.

7. Kanaan NC, Ray J, Stewart M, Russell KW, Fuller M, Bush SP, et al. Wilderness Medical Society practice guidelines for the treatment of pitviper envenomations in the United States and Canada. Wilderness Environ Med. 2015;26(4):472-87.

8. Moore B, Slone T. Kentucky Snakes. Frankfort, KY: Kentucky Dept. of Fish and Wildlife Services; 2004.

9. Fatah C. Pathophysiological and pharmacological effects of snake venom components: molecular targets. J Clin Toxicol. 2014;4(2).

10. McCleary RJR, Kini RM. Snake bites and hemostasis/ thrombosis. Thromb Res. 2013;132(6):642-6.

11. Gerardo CJ, Quackenbush E, Lewis B, Rose SR, Greene S, Toschlog EA, et al. The efficacy of crotalidae polyvalent immune fab (ovine) antivenom versus placebo plus optional rescue therapy on recovery from copperhead snake envenomation: a randomized, double-blind, placebo-controlled, clinical trial. Ann Emerg Med. 2017;70(2):233-4.e3.

12. US Food and Drug Administration. Package Insert - CROFAB - FDA. Available at: www.fda.gov/downloads/Biologics BloodVaccines/BloodBloodProducts/Approved Products/ LicensedProductsBLAs/FractionatedPlasmaProducts/ucm 117573.pdf. Accessed September 15, 2018.

13. Gale SC, Peters JA, Allen L, Creath R, Dombrovskiy VY. FabAV antivenin use after copperhead snakebite: clinically indicated or knee-jerk reaction? J Venom Anim Toxins Incl Trop Dis. 2016;22:2.

14. Lavonas EJ, Ruha A, Banner W, Berbarta V, Bernstein JN, Bush S, et al. Unified treatment algorithm for the management of crotaline snakebite in the United States: results of an evidence-informed consensus workshop. BMC Emerg Med. 2011;11:2.

15. Lavonas EJ, Schaeffer TH, Kokko J, Mlynarchek SL, Bogdan GM. Crotaline fab antivenom appears to be effective in cases of severe North American pit viper envenomation: an integrative review. BMC Emerg Med. 2009;9:13.
16. Pressure immobilization after North American Crotalinae snake envenomation. Clin Toxicol (Phila). 2011;49(10):881-2.

17. LoVecchio F, Klemens J, Welch S, Rodriguez R. Antibiotics after rattlesnake envenomation. $J$ Emerg Med. 2002;23(4):327-8.

18. Joslin JD, Marraffa JM, Singh H, Mularella J. Incidence and characteristics of snakebite envenomations in the New York state between 2000 and 2010. Wilderness Environ Med. 2014;25(3):289-94.

19. Harmon KJ, Haskell MG, Mann CH, Waller AE. Snakebites treated in North Carolina emergency departments, October 2013-September 2015. Wilderness Environ Med. 2018;29(2):176-84.

20. Ruha A, Kleinschmidt KC, Greene S, Spyres MB, Brent J, Wax P, et al. The epidemiology, clinical course, and management of snakebites in the North American snakebite registry. J Med Toxicol. 2017;13(4):309-20.

21. Langley R, Haskell MG, Hareza D, King K. Fatal and nonfatal snakebite injuries reported in the United States. South Med J. 2020;113(10):514-9.

22. Anz AW, Schweppe M, Halvorson J, Bushnell B, Sternberg M, Koman LA. Management of venomous snakebite injury to the extremities. J Am Acad Orthop Surg. 2010;18(12):749-59.

23. Toschlog EA, Bauer CR, Hall EL, Dart RC, Khatri V, Lavonas EJ. Surgical considerations in the management of pit viper snake envenomation. J Am Coll Surg. 2013;217 (4):726-35.

24. Baumgartner KT, Fishburn SJ, Mullins ME. Current management of copperhead snakebites in Missouri. Mo Med. 2019;116(3):201-5.

25. Pugh KH, Kelsey A, Tominack R. Comparing syndromic surveillance and poison center data for snake bites in Missouri. Online J Public Health Inform. 2013;5(1):e102.

26. Corbett SW, Anderson B, Nelson B, Bush S, Hayes WK, Cardwell MD. Most lay people can correctly identify indigenous venomous snakes. Am $J$ Emerg Med. 2005;23(6):759-62. 